\title{
On Watching Screendance
}

Sherril Dodds, Temple University

\begin{abstract}
In this provocation, I ask what is it to watch screendance, what is at stake, and what comes into play? I suggest that in identifying works as examples of "dance on screen", we enter into a complex history of aesthetic innovations, marketing criteria, funding systems, and intellectual debates. I compare the viewing practices of film, television and the internet, and consider how different screen formats shape experiences of teaching and research. I reflect upon the ethics of participation in online debates, and suggest that the modes and stakes of watching are as important as the dance itself.
\end{abstract}

Keywords: watching, research, teaching, consumption, participation

What is it to watch?

What is at stake?

What comes into play?

To say that we are watching screendance assumes that we can identify the very character of screendance. Operational categories certainly exist that organize screendance into generic groupings: dance documentary, film musical, pop music video, dance commercial, reality television show, dance for camera, Bollywood film, television adaptation, experimental dance film, TV dance competition, Hollywood dance film, dance animation, and so on. Yet the borders of these typologies fail to hold as tropes and techniques slip from one category to another. Boundaries become fluid and genres resist easy definition. And while the term "screendance" might serve as a useful placeholder that gently and inclusively holds together a multitude of screen works that feature "dance," it may also include representations that complicate common conceptions of dance. Such screen works do not necessarily employ explicit images of dancing people, but instead are attentive to the choreographic sensibilities of film-making (the movement of the camera and rhythm of the cut) and the quality of movement per se (the motion of inanimate objects or non-human mobile subjects). Therefore in naming our viewing choice as screendance, we enter into a complex history of aesthetic innovations, marketing criteria, funding systems, and intellectual debates. For artists and scholars, the naming and claiming of screendance gives visibility to that which we hold dear both aesthetically and politically. 
Opportunities to watch screendance differ considerably from when and how I watched it as a young viewer to how I watch it now. As a child I walked to our local cinema to witness the spectacle of dance in the movies, often returning at a later date for a repeat viewing of my favorite dance films. Alternatively, I scoured through the entertainment sections of the newspaper to catch television programs that featured dance. In my teens, the luxury of home video allowed the opportunity to sit by the VHS player all set to press "record" seconds before the television show started, and then watch these scratchy images many times over. While a graduate student, in my mid-twenties, I needed to employ social and economic capital to study the screendance to which I would otherwise have limited or no access. A friend who worked in advertising managed to find out which agency had produced a Hellmann's mayonnaise commercial that featured dance. I called the agency, tracked down the person who negotiated the "spot times" during which the ads would run, and then dutifully set my video machine to record them, keeping my fingers crossed that the information was accurate. I rang several travel agencies to find the cheapest return airfare to Monaco so that I could attend the annual IMZ Dancescreen festival, spending almost the entire three days isolated in small viewing cubicles so that I could watch as many of the entries as possible, the majority of which would never be screened on British television. I made extensive notes trying to imprint the style and content of punchy little dance films onto my mind's eye. And through a wonderful connection, brokered by my dissertation adviser, to BBC television producer Bob Lockyer, I gained a day's access to the BBC archives where I watched grainy black and white recordings of dance films from the mid-twentieth century. On the bus home, I read through more reams of notes and carefully held on to a VHS copy of Houseparty (1964), an early example of dance designed for television, that the BBC archivist had kindly run off for me. The magic of those one-off viewings and the satisfaction of watching poor quality video recordings many times over characterized my early research life.

As I entered university teaching in the late 1990s, the technical paraphernalia of how to enable my students to watch screendance proved equally challenging. I would prepare for lectures by sitting in a large closet that served as the dance department video library diligently compiling video clips onto a single VHS tape as someone had managed to hook up two recorders that enabled tape-to-tape recording. I spent hours fastforwarding, rewinding and recording in private, but at least this saved the awkward time in a class fumbling around with multiple tapes or holding down the fast-forward button to cycle through different sections of a dance. Even as DVDs became commercially available, the temperamental university machines would not always play them or allow me to cue a certain point in a dance. And although I had built up a huge personal video library neatly catalogued through a numerical system that tallied with hand-written index cards that detailed the title, dance company, director, choreographer, creation date, and other pertinent information, I ditched the entire collection when I relocated to the United States. The loss of my precious video archive still gives me shivers, 
however most universities no longer provide video players in their classrooms, and my British PAL tapes were not compatible with the American NTSC machines. While I had been slowly transferring some of my most beloved recordings onto DVD in the year or so prior to my departure, most of these now sit in the bottom of my office filing cabinet as the US region 1 players at my university will not accommodate my European region 2 discs. Although I am a little sad about this, and want to recognize the emotional relationship that we invest in the physical artifacts that facilitate our teaching and research, the development of digital technologies and the internet have utterly transformed what we watch and how we watch screendance.

On arriving in the United States in 2011, I decided at that point that I would no longer mess around with tapes and discs, but would only use teaching materials that I could access online. The sheer quantity of screendance available online, through free video platforms such as YouTube and Vimeo and curated subscription sites such as Alexander Street, proves almost overwhelming. Indeed the shift from scanning the newspapers for rare glimpses of screendance to the deluge of dance through digital means is staggering. While this greater level of access to watching, making, and learning dance has sometimes been couched within a rhetoric of democratization, this needs to be accompanied with caution. Some sections of the population either remain without access to, or elect not to engage with, the internet, although it is widely available in schools, universities, and public libraries. And though many sites are open access, some require membership fees, thus excluding those with limited economic means.

In addition to increased availability of screendance, greater opportunities to engage in its production have come about through low-cost digital recording devices that we can carry around in our pockets. Again, not everyone has access to smartphones or GoPros; however, a substantial proportion of the population has the capacity to capture dance images on screen whether simply pointing and shooting dance at a family wedding or using playful production techniques to curate and manipulate moving bodies. Consequently, greater access to the means of production enables voices and bodies to be seen and heard that may have otherwise been overlooked through the taste and value structures of a limited pool of commissioning editors responsible for screendance within public broadcasting networks. A similar sense of diversification comes about through the ways in which we might learn dance through screen tutorials. Whereas throughout the 1980s and 90s, a limited number of commercially available dance instruction videos benefited from mass circulation through those with concomitant social and economic capital (although dances were also transmitted within grassroots communities through DIY video-making), we can now access tutorials on just about any topic imaginable through amateur teaching on YouTube. Though we always need to check the authority and expertise of dance teaching, the abundance of online videos affords us plenty of opportunity for cross checking and validating the reliability of sources. 
Yet the excess, the overload, and the seemingly infinite leave me unsettled. I am no longer left hungry for more, but instead feel utterly saturated. This endless quantity clearly re-shapes how I watch. While the big screen continues to thrive, the option to 'watch again' through Netflix or Hulu leaves me spoilt for choice and struggling to decide what to watch. I see people watching feature films on tablets, laptops and phones in bright and bustling public environments far removed from the quiet intimacy of a blacked-out movie theater. While I want to avoid the simplistic binary that cinema spectatorship always ensures a focused and complete viewing experience whereas watching television or the digital screen is distracted and fragmented in comparison, the range of options regarding what and where we watch makes me think twice about contemporary viewing habits. I fear my capacity to sit and watch carefully is usurped by the need to scan quickly and keep moving through the virtual viewing landscape. I worry that my patience and tolerance are constantly tested and that, unless a film can hold my attention through novelty, brevity, and spectacle then I will move on to the next piece of click bait. Of course I need to remind myself that as a dance researcher with my own values and interests, I might attentively watch a long passage of screendance (such as a poor resolution and fixed camera recording of an entire hip-hop battle) that would be of little interest to those outside this taste community. The point is that it is available. Furthermore, I can easily locate all manner of dance commercials, music videos, and experimental dance films that were extremely difficult to track down twenty-five years ago. Although I keep returning to the caveat that not all dance is accessible online and not all people have online access, exponentially more screendance exists in the digital realm than in the analog days of my early research. The research process might be less exciting, but the research findings remain so.

Excitement aside, I also think about the ethics of our engagement with screendance online. Unlike cinema and television, online spectatorship frequently offers space for feedback and commentary. A quick glance through the viewer comments posted below video clips reveals all kinds of wonderful and wacky responses that range from truly enlightened to horribly toxic, depending upon one's position and politics. This prompts me to question whether watching should be an end in itself or whether we should frame our response in dialogue with other spectators. When dance clips are taken out of context or comments reveal naïve assumptions or dangerous perceptions about dance on screen, do we have an ethical responsibility to intervene? In a digital landscape in which images and words, spectatorship and interpretation, are placed in such close relationship, do we simply approach this material as valuable research data or do we take on the role of expert interlocutors willing to inform and take a stand? This might depend on whether our emotional and intellectual investments are resilient enough to withstand all kinds of voices and perceptions, which can speak loudly and forcibly in the digital realm. Yet another option asks us to wait patiently until new screendance work begins to circulate that speaks back to us through the artistry and motion of its own visual and kinetic language. The work itself then enters into conversation with what has 
come before. Whether we speak our politics blatantly or live them quietly through how we move in the world, we take a position on the screendance that surrounds us: we choose what, how, where, when and why we watch.

The screen clearly orients us to watch dance under specific historical, technological, and social conditions, which in turn shape how we invest in and value screendance, our practices of spectatorship, and how we might learn from it or share it with others. Through understanding these frameworks of consumption, reception, and participation, we then have the option to choose how we engage with screendance and to what end. Often students joke that I have killed any pleasure in watching as I redirect their attention to the technical and aesthetic apparatus that construct images of dance on screen, thus bringing into focus the politics of representation. While I try to reassure them that they can still indulge in scopic pleasures and spectacular desires, film studies tells us that visual pleasure is itself a social construction. Contemporary audiences are fortunate to have an excess of screendance from different historical eras, national contexts, and of diverse artistic styles that satisfy a wide spectrum of tastes and interests. For screendance studies, however, thinking about the modes and stakes of watching is perhaps as important as the dance itself.

\section{Biography}

Sherril Dodds is a Professor of Dance at Temple University. Her books include Dance on Screen (2001), Dancing on the Canon (2011), Bodies of Sound (co-edited with Susan C. Cook, 2014), The Oxford Handbook of Dance and Competition (2019) and The Bloomsbury Companion to Dance Studies (2019). She has been a visiting scholar at Trondheim University in Norway, Griffith University in Australia, Stanford University in the USA, and Blaise-Pascal University in France. She was awarded the 2015 Gertrude Lippincott prize for her article, 'The Choreographic Interface: Dancing Facial Expression in Hip Hop and Neo-burlesque striptease'.

Email: sherril.dodds@temple.edu

\section{Reference}

Houseparty (1944). Dir. Margaret Dale. TV movie. 1964. BFI. 